\title{
Cerebral Oxygen Metabolic Stress, Microstructural Injury, and Infarction in Adults With Sickle Cell Disease
}

Yan Wang, MD,* Slim Fellah, PhD,* Melanie E. Fields, MD, MSCl, Kristin P. Guilliams, MD, MSCl, Michael M. Binkley, PhD, MS, Cihat Eldeniz, PhD, Joshua S. Shimony, MD, PhD, Martin Reis, MD, Katie D. Vo, MD, Yasheng Chen, DSc, Jin-Moo Lee, MD, PhD, Hongyu An, DSc, and Andria L. Ford, MD, MSCI

Neurology ${ }^{\circledR}$ 2021;97:e902-e912. doi:10.1212/WNL.0000000000012404

\section{Abstract}

\section{Objective}

To determine the patient- and tissue-based relationships between cerebral hemodynamic and oxygen metabolic stress, microstructural injury, and infarct location in adults with sickle cell disease (SCD).

\section{Methods}

Control participants and patients with SCD underwent brain MRI to quantify cerebral blood flow (CBF), oxygen extraction fraction (OEF), mean diffusivity (MD), and fractional anisotropy (FA) within normal-appearing white matter (NAWM) and infarcts on fluid-attenuated inversion recovery. Multivariable linear regression examined the patient- and voxel-based associations between hemodynamic and metabolic stress (defined as elevated CBF and OEF, respectively), white matter microstructure, and infarct location.

\section{Results}

Of 83 control participants and patients with SCD, adults with SCD demonstrated increased CBF (50.9 vs $38.8 \mathrm{~mL} / \mathrm{min} / 100 \mathrm{~g}, p<0.001)$, increased OEF (0.35 vs $0.25, p<0.001$ ), increased $\mathrm{MD}\left(0.76\right.$ vs $\left.0.72 \times 10^{-3} \mathrm{~mm}^{2} \mathrm{~s}^{-1}, p=0.005\right)$, and decreased FA ( 0.40 vs $0.42, p=$ 0.021 ) within NAWM compared to controls. In multivariable analysis, increased OEF ( $\beta=$ $0.19, p=0.035)$, but not $\mathrm{CBF}(\beta=0.00, p=0.340)$, independently predicted increased MD in the SCD cohort; neither were predictors in controls. On voxel-wise regression, the SCD cohort demonstrated widespread OEF elevation, encompassing deep white matter regions of elevated $\mathrm{MD}$ and reduced FA, which spatially extended beyond high-density infarct locations from the SCD cohort.

\section{Conclusion}

Elevated OEF, a putative index of cerebral oxygen metabolic stress, may provide a metric of ischemic vulnerability that could enable individualization of therapeutic strategies in SCD. The patient- and tissue-based relationships between elevated OEF, elevated MD, and cerebral infarcts suggest that oxygen metabolic stress may underlie microstructural injury prior to the development of cerebral infarcts in SCD.

\author{
Correspondence \\ Dr. Ford \\ forda@wustl.edu
}

\section{RELATED ARTICLE}

Editorial

Not-So-Normal-Appearing White Matter

Page 409

MORE ONLINE

(c) Infographic

http://links.lww.com/WNL/ B479

*These authors contributed equally to this work as co-first authors.

From the Department of Neurology (Y.W., S.F., M.M.B., J.-M.L., H.A., A.L.F.), Division of Pediatric Hematology/Oncology (M.E.F.), Division of Pediatric Neurology (K.P.G.), and Mallinckrodt Institute of Radiology (C.E., J.S.S., M.R., K.D.V., Y.C., J.-M.L., H.A., A.L.F.), Washington University School of Medicine, St. Louis, MO.

Go to Neurology.org/N for full disclosures. Funding information and disclosures deemed relevant by the authors, if any, are provided at the end of the article. 


\section{Glossary}

ASE = asymmetric spin echo; $\mathbf{C B F}=$ cerebral blood flow; $\mathbf{C I}=$ confidence interval; $\mathbf{D T I}=$ diffusion tensor imaging; FA = fractional anisotropy; FLAIR = fluid-attenuated inversion recovery; $\mathrm{HbAA}=$ without sickle cell trait; $\mathrm{HbAS}=$ with sickle cell trait; HbSC = hemoglobin SC; HbSS = hemoglobin SS; MD = mean diffusivity; MIPAV = Medical Image Processing, Analysis, and Visualization; MNI = Montreal Neurologic Institute; MPRAGE = magnetization-prepared rapid gradient echo; NAWM = normal-appearing white matter; $\mathbf{O E F}=$ oxygen extraction fraction; $\mathbf{p C A S L}=$ pseudocontinuous arterial spin labeling; $\mathbf{S C D}=$ sickle cell disease; $\mathbf{S N R}=$ signal-to-noise ratio; $\mathbf{T E}=$ echo time; $\mathbf{T I}=$ inversion time; $\mathbf{T R}=$ repetition time.

Sickle cell disease (SCD) is a group of inherited hemoglobinopathies that affects 1 in 1,000 individuals worldwide. ${ }^{1}$ The abnormal erythrocytes have decreased oxygen carrying capacity and increased rigidity, leading to microvascular obstruction and multiorgan ischemia. In the brain, pathologic consequences of these mechanisms include ischemic strokes and cognitive impairment. Although the incidence of overt strokes has decreased in the era of transcranial Doppler screening and prophylactic transfusion therapy, ${ }^{2}$ the prevalence of silent cerebral infarcts continues unabated. On brain MRI, over $50 \%$ of adults with SCD demonstrate silent infarcts by age $32 .{ }^{3}$ Regardless of clinical presentation, cerebral infarcts are associated with cognitive deficits in children and young adults with $\mathrm{SCD} .{ }^{4,5}$

Cerebral infarcts in SCD may result, in part, from oxygen supply-demand mismatch. We and others have shown that global cerebral blood flow $(\mathrm{CBF})$ and the fraction of oxygen that diffuses from blood to tissue (oxygen extraction fraction $[\mathrm{OEF}]$ ) are increased in patients with SCD. ${ }^{6-8}$ Such elevation in CBF and OEF compensate for decreased arterial oxygen content in SCD and to meet cerebral oxygen metabolic demand. However, the brain's compensatory capacity is heterogeneous and demonstrates regional vulnerability to ischemic-hypoxic insult. ${ }^{9}$ Cerebral infarcts most commonly occur in the physiologic watershed territory, characterized by low white matter CBF compared to the rest of the brain. ${ }^{6,7}$ We have previously shown that elevated watershed $\mathrm{OEF}$ is associated with increased infarct density from an independent SCD cohort, ${ }^{7}$ suggesting that regional $\mathrm{CBF}$ and OEF may represent "hemodynamic and oxygen metabolic stress," respectively, and may hold promise as markers of increased stroke risk.

With a goal of identifying cerebral ischemic injury at its earliest stages, diffusion tensor imaging (DTI) has allowed the assessment of white matter microstructural integrity in SCD. ${ }^{10-12}$ Microstructural impairment in patients with SCD has been associated with slower processing speed, independent of infarcts. ${ }^{13,14}$ Likewise, several studies in nonSCD sporadic cerebral small vessel disease have shown that changes in microstructure may predict progression of white matter hyperintensities and cognitive decline. ${ }^{15,16}$

Quantifying degree of microstructural impairment has been of interest in SCD, but the pathomechanisms underlying its disruption and its spatiotemporal relationship to developing infarcts are not well understood. In this study, we examined the effect of hemodynamic and oxygen metabolic stress on white matter microstructure within normal-appearing white matter (NAWM), unaffected by infarcts, in adults with SCD compared to healthy controls. We hypothesized that (1) elevated CBF and OEF would be independently associated with impairment in NAWM microstructure and (2) regions of greatest microstructural impairment would be located in and nearby regions of peak infarct density, suggesting microstructural impairment may be a precursor to cerebral infarcts in SCD.

\section{Methods}

\section{Standard Protocol Approvals, Registrations, and Patient Consents}

The Institutional Review Board at Washington University in St. Louis approved this study and written informed consent was obtained from all participants.

\section{Participants}

Adult participants with SCD and healthy controls were prospectively enrolled in a longitudinal MRI study. A subset of participants returned for follow-up MRI at 3 years after the baseline MRI scan. Participants with SCD included hemoglobin SS (HbSS), HbS $\beta$-thalassemia, and hemoglobin SC (HbSC). Control participants included siblings, partners, or friends of participants with SCD to minimize imbalances in socioeconomic status and parental education level, which have been shown to affect cognitive function in SCD. ${ }^{17}$ In an effort to include sibling controls, the control cohort included both participants with sickle cell trait (HbAS) and participants without sickle cell trait (HbAA). Exclusion criteria were history of stem cell transplantation, cerebral vasculopathy, cerebral infarct volume $>5 \mathrm{~mL}$, or intracerebral hemorrhage. Controls were also excluded for any history of neurologic disease or chronic medical condition (i.e., hypertension) associated with stroke. A board-certified neuroradiologist (M.R.), blinded to cohort, diagnosis, and baseline characteristics, reviewed all MRIs and magnetic resonance angiograms for evaluation of cerebral infarcts or vasculopathy. Participants with infarcts were classified as (1) overt strokes, defined as a clinical history of nonhemorrhagic stroke associated with clinical symptoms; or (2) silent cerebral infarcts, defined as nonovert strokes with cerebral lesions $\geq 3 \mathrm{~mm}$ in diameter on axial plane of fluid-attenuated inversion recovery (FLAIR) images. ${ }^{18}$ 
Laboratory studies including venous hemoglobin, capillary gel electrophoresis to quantify percentage of hemoglobin isoforms, and venous co-oximetry and vital signs including oxygen saturation by pulse oximetry $\left(\mathrm{SpO}_{2}\right)$ were obtained just before each MRI. Dyshemoglobins were missing in 2 controls and 5 participants with SCD. Arterial oxygen content $\left(\mathrm{CaO}_{2}\right)$ was calculated as $1.36 \times$ hemoglobin $(\mathrm{g} / \mathrm{dL}) \times \mathrm{SpO}_{2}$. Hemoglobin used in $\mathrm{CaO}_{2}$ calculation was adjusted according to the following formula: hemoglobin $=[$ total measured hemoglobin $]-[$ total hemoglobin $\times \%$ carboxyhemoglobin $]-[$ total hemoglobin $\times \%$ methemoglobin]. Dyshemoglobins (carboxyhemoglobin and methemoglobin), which are elevated in SCD, do not participate in oxygen exchange and were subtracted from total hemoglobin. ${ }^{19}$

\section{MRI Protocol and Imaging Analysis}

All participants underwent brain MRI on a 3T Siemens MRI system, including 3 scanner types: Magnetom Trio, Magnetom Prisma, and Biograph mMR. The MRI protocol included T1 3D magnetization-prepared rapid gradient echo (MPRAGE) (echo time [TE]/repetition time $[\mathrm{TR}]=2.95 /$ $1,800 \mathrm{~ms}$, inversion time $[\mathrm{TI}]=1,000 \mathrm{~ms}$, flip angle $=8^{\circ}$, resolution $=1.0 \times 1.0 \times 1.0 \mathrm{~mm})$, FLAIR $(\mathrm{TE} / \mathrm{TR}=93 / 9,000$ $\mathrm{ms}, \mathrm{TI}=2,500 \mathrm{~ms}$, resolution $=1.0 \times 0.9 \times 3.0 \mathrm{~mm})$, DTI $(\mathrm{TE} / \mathrm{TR}=89 / 10,100 \mathrm{~ms}$, resolution $=2.0 \times 2.0 \times 2.0 \mathrm{~mm}, 25$ directions, $\mathrm{b}=0-1,400$ seconds $\left./ \mathrm{mm}^{2}\right)$, pseudocontinuous arterial spin labeling ( $\mathrm{pCASL})(\mathrm{TE} / \mathrm{TR}=12 / 3,780 \mathrm{~ms}$, resolution $=3.0 \times 3.0 \times 5.0 \mathrm{~mm}$, labeling duration $=2,000 \mathrm{~ms}$, postlabeling delay $=1,500 \mathrm{~ms}$, background suppression not performed), and a double-echo asymmetric spin echo (ASE) sequence $(\mathrm{TE} / \mathrm{TR}=64.0 / 4,400 \mathrm{~ms}$, field of view $220 \mathrm{~mm}$, resolution $=1.7 \times 1.7 \times 3.0 \mathrm{~mm}$, acquisition time $=7: 16)$.

For each participant, a white matter mask, gray matter mask, and infarct mask were generated to respectively represent the total white matter region, gray matter region, and infarcted region of that participant. To generate a NAWM mask, all voxels within the infarct mask were excluded from white matter mask. First, cerebral infarcts were identified by a boardcertified neuroradiologist (M.R.) and delineated on FLAIR images by a board-certified vascular neurologist (A.L.F.) using the Medical Image Processing, Analysis, and Visualization (MIPAV; mipav.cit.nih.gov/) application to create 1 infarct mask per participant. MIPAV includes a semiautomated approach to delineating infarct lesions, allowing the user to hover over an infarct lesion with the cursor, and the bright region is automatically outlined based on contrasting signal intensity. Both the identification and delineation of infarct masks were performed in a blinded fashion without knowledge of the participant's cohort. Second, to generate white and gray matter masks, MPRAGE images were skullstripped and segmented using statistical parametric mapping software (SPM12, Wellcome Institute of Neurology). ${ }^{20}$ To limit partial volume effects, voxels with a probability $<0.9$ of being classified correctly as white or gray matter were excluded and a 1-voxel morphologic erosion of gray and white matter was applied to segmented images. $^{21}$ The generation of NAWM mask allowed for regional measurements of $\mathrm{CBF}, \mathrm{OEF}$, and DTI metrics within NAWM unaffected by infarcts.

CBF was measured with pCASL. ${ }^{22}$ Blood T1, required for CBF quantification, varies with hematocrit, and thus was measured individually to improve $\mathrm{CBF}$ reproducibility. ${ }^{23}$ Blood $\mathrm{T} 1$ was measured using an inversion-recovery echoplanar imaging sequence, with an adiabatic nonselective inversion pulse, in the superior sagittal sinus and estimated using a 4-parameter model. ${ }^{24}$ Blood T1 was not acquired in 6 scans and was imputed based on a larger dataset of patients with SCD and controls in which we performed a multivariable analysis examining clinical predictors (such as age, sex, and hematocrit) of blood T1. This model demonstrated hematocrit as the main predictor of T1, which has been found in other studies. ${ }^{25}$ ASE measured tissue deoxyhemoglobin, permitting OEF quantification as described previously. ${ }^{26,27}$ Censorship of voxels exhibiting abnormal $\chi^{2}$ residuals, as a metric of high error when calculating OEF, was required to prevent spurious results. An a priori nonparametric unidirectional exclusion of all data producing residuals above the 65 th percentile of the white matter, as a result of the Gibbs artifact affecting primarily gray matter, was applied. Representative CBF and OEF maps are shown in eFigure 1 (doi.org/10.5061/dryad.79cnp5hv5). Individual mean CBF and OEF within whole brain, gray matter, and NAWM were calculated.

Diffusion tensor images were processed using the FMRIB Software Library (fmrib.ox.ac.uk/fsl, v6.0). ${ }^{28}$ Briefly, for each scan, diffusion images were corrected for eddy current distortion and head motion using the $b=0$ reference image. A binary brain mask in DTI space was then calculated using FSL's Brain Extraction Tool on the same $b=0$ image. DTIfit ${ }^{29}$ was then applied to fit the diffusion tensor model, ${ }^{30}$ generating the 3 principal eigenvalues $\lambda_{1}, \lambda_{2}, \lambda_{3}$ at each voxel. Finally, measures of white matter microstructure, average fractional anisotropy (FA), and mean diffusivity (MD) in NAWM were calculated.

To create an infarct heatmap demonstrating the location and density of infarcts, all infarct masks from the SCD cohort were aligned to the Montreal Neurologic Institute (MNI) 152 standard space. Infarct density was defined as the number of participants with infarct in the voxel divided by total number of participants. Three participants were excluded due to poor registration of the lesion mask to the atlas, thus 31 participants with SCD were included in the infarct heatmap.

\section{Statistical Analysis}

\section{Patient-Based Analysis}

Data are presented as median (interquartile range). Clinical characteristics, laboratory measures, and baseline imaging measures were compared between healthy controls and participants with SCD using Mann-Whitney $U$ or Fisher exact test for continuous and categorical variables, respectively. Given the significant age and sex imbalance between the 2 cohorts, 
baseline imaging measures were compared between the 2 cohorts before and after adjusting for age and sex using multivariable linear regression analysis. To account for multiple testing, significance was adjusted to maintain a family-wise error rate $<5 \%$ using the Benjamini-Hochberg procedure.

To measure the univariate relationships between oxygen metabolic and hemodynamic stress and microstructural impairment, bivariate correlations between $\mathrm{OEF} / \mathrm{CBF}$ and $\mathrm{MD}$ / FA in NAWM were performed with Pearson correlation coefficients. To evaluate $\mathrm{OEF}$ and $\mathrm{CBF}$ as independent predictors of impaired NAWM microstructure, all imaging time points (a subset of participants had 2 scans) were included in a mixed-model multivariable linear regression with random participant intercept. For the mixed model, NAWM OEF/ $\mathrm{CBF}$, age, and scanner type were entered as predictor variables, while NAWM MD and NAWM FA were the outcome variables. Scanner type was included as a predictor variable given interscanner variation in DTI metrics has been observed. $^{31,32}$ Effect plots demonstrate the relationships between NAWM OEF/CBF and DTI metrics, while controlling for age, participant effect with multiple MRI scans, and scanner type. Significance was set at $p<0.05$. Patient-based analyses were performed with SAS (v9.4, SAS Institute Inc.).

\section{Voxel-wise Analysis}

Each participant's baseline OEF, MD, and FA images were aligned to individual MPRAGE images using FMRIB's Linear Image Registration Tool (FLIRT) and transformed into MNI 152 space using nonlinear registration methods. CBF was not included as it was not an independent predictor of NAWM microstructure in the patient-based analysis. For each MRI modality, a 4D image was created by merging individual images. The 4D image was then fed into FSL Randomise to perform voxel-wise statistics.

Voxel-wise differences between SCD and controls in FA, MD, and OEF were tested over the white matter using permutationbased FSL Randomise ${ }^{33,34}$ with threshold-free cluster enhancement $^{35}$ and 10,000 random permutations to adjust for multiple statistical comparisons. This method produced nonparametric permutation, 2-sample, unpaired $t$ tests of MRI metrics in participants with SCD compared to controls, adjusted for age and scanner type. Results were considered significant for $p<0.05$.

\section{Data Availability}

Data are available on request to the corresponding author.

\section{Results}

\section{Patient Characteristics}

Eighty-three participants (34 adults with SCD and 49 healthy controls) underwent brain MRI. Each participant had 1 MRI scan except for 4 controls and 16 participants with SCD who had 2 MRI scans. All participants with SCD had HbSS genotype
Table 1 Baseline Participant Characteristics

\begin{tabular}{|c|c|c|c|}
\hline & $\begin{array}{l}\text { Control } \\
\text { cohort } \\
(n=49)\end{array}$ & $\begin{array}{l}\text { SCD cohort } \\
(n=34)\end{array}$ & $p$ Value \\
\hline Age, y & $33.0(28.5-37.0)$ & $22.0(19.0-28.0)$ & $\leq 0.001^{c}$ \\
\hline Sex, female & $36(73)$ & $15(44)$ & $0.01^{c}$ \\
\hline Race, African American & $49(100)$ & $34(100)$ & 1.0 \\
\hline Hemoglobin, g/dL & $12.5(11.8-13.6)$ & $9.0(7.9-9.7)$ & $\leq 0.001^{c}$ \\
\hline Hemoglobin S, \% ${ }^{a}$ & $0(0-37.3)$ & $71.2(49.6-84.0)$ & $\leq 0.001^{c}$ \\
\hline Hemoglobin F, \% & $0.4(0.2-0.4)$ & $3.8(1.8-14.95)$ & $\leq 0.001^{c}$ \\
\hline сонb, \% & $1.0(0.7-2.0)$ & $2.9(2.1-3.7)$ & $\leq 0.001^{\mathrm{c}}$ \\
\hline MetHb, \% & $1.2(0.6-1.6)$ & $1.9(1.5-2.6)$ & $\leq 0.001^{c}$ \\
\hline $\mathrm{SpO}_{2}, \%$ & $99(98-100)$ & $98(95-99.5)$ & $0.001^{c}$ \\
\hline $\mathrm{CaO}_{2}, \mathrm{~mL} / \mathrm{dL}$ & $16.2(15.5-17.7)$ & $11.29(9.3-12.1)$ & $\leq 0.001^{c}$ \\
\hline \multicolumn{4}{|l|}{ Radiographic infarct } \\
\hline Present & $19(39)$ & $21(62)^{a}$ & $0.047^{c}$ \\
\hline Overt stroke in SCD & - & $5(24)$ & - \\
\hline$S C I$ in SCD & - & $16(76)$ & - \\
\hline Infarct volume, mL & $0(0-0.09)$ & $0.35(0.03-1.10)$ & $\leq 0.001^{c}$ \\
\hline \multicolumn{4}{|l|}{$\begin{array}{l}\text { Primary disease } \\
\text { modification, SCD }\end{array}$} \\
\hline None & - & $9(26)$ & \\
\hline Hydroxyurea & - & $18(53)^{\mathrm{b}}$ & \\
\hline Chronic transfusion & - & $9(26)$ & \\
\hline
\end{tabular}

Abbreviations: $\mathrm{CaO}_{2}=$ arterial oxygen content; $\mathrm{COHb}=$ carboxyhemoglobin; MetHb = methemoglobin; $\mathrm{SCD}=$ sickle cell disease; $\mathrm{SCl}=$ silent cerebral infarct; $\mathrm{SpO}_{2}=$ peripheral oxygen saturation.

Values are median (interquartile range) or $\mathrm{n}(\%)$.

a The control cohort included 26 participants with $\mathrm{HbAA}$ and 23 with $\mathrm{HbAS}$.

${ }^{\mathrm{b}}$ Two participants received hydroxyurea and chronic transfusion therapy.

'Significant.

except 2 with $\mathrm{HbSC}$. The control cohort consisted of 26 participants with $\mathrm{HbAA}$ and 23 with $\mathrm{HbAS}$. Participant characteristics are included in Table 1 . Due to imbalance in age between controls and SCD cohorts, all analyses were performed before and after adjusting for age. No significant univariate associations were found between age and DTI measures examined in the study (eFigure 2 [doi.org/10.5061/dryad.79cnp5hv5]). As sickle cell trait was permitted in the control cohort, we compared the imaging measures (OEF, CBF, MD, and FA) between $\mathrm{HbAA}$ and $\mathrm{HbAS}$. We found no differences or statistical trends between the control participants with and without sickle cell trait (data not shown).

\section{Cerebral OEF and CBF Within NAWM Were Increased in Adults With SCD}

To determine whether cerebral oxygen metabolic and hemodynamic stress were elevated within NAWM, we compared 
baseline OEF and CBF in NAWM between adults with and without SCD. Cerebral OEF and CBF in NAWM were elevated in the SCD cohort compared to controls (Table 2 ). This elevation in OEF persisted in the SCD cohort after adjusting for age and sex (SCD cohort: $\beta$ [95\% confidence interval $(\mathrm{CI})]=0.13[0.11,0.15], p \leq 0.001$; age: $\beta[95 \%$ $\mathrm{CI}]=-0.0003[-0.002,0.001], p=0.70$; male: $\beta[95 \% \mathrm{CI}]$ $=-0.05[-0.07,-0.03], p \leq 0.001)$. Likewise, $\mathrm{CBF}$ remained elevated in the SCD cohort after adjusting for age and sex on multivariable linear regression analysis (SCD cohort: $\beta[95 \% \mathrm{CI}]=19.41[12.61,26.21], p \leq 0.001$; age: $\beta$ $[95 \% \mathrm{CI}]=0.29[-0.14,0.71], p=0.18$; male: $\beta[95 \% \mathrm{CI}]=$ $0.16[-6.08,6.39], p=0.96)$. Similar patterns of OEF and CBF elevation in the SCD cohort were identified in wholebrain and gray matter regions (Table 2).

\section{Adults With SCD Demonstrated Impairment in NAWM Microstructure}

To examine the microstructural integrity of NAWM in SCD, baseline DTI metrics (MD, FA) were compared between the 2 cohorts before and after adjusting for age and sex. Compared with controls, NAWM MD was higher (0.76 [0.74, $0.78]$ vs $\left.0.7210[0.70,0.77] \times 10^{-3} \mathrm{~mm}^{2} \mathrm{~s}^{-1}, p=0.005\right)$ and NAWM FA was lower $(0.40[0.40,0.42]$ vs $0.42[0.40-0.43]$, $p=0.021$ ) in participants with SCD (Table 2), suggesting impaired white matter microstructure despite the younger age of the SCD cohort. The microstructural integrity of NAWM remained altered in the SCD cohort after adjusting for age and sex on multivariable analysis: $\mathrm{MD}$ remained elevated (SCD cohort: $\beta[95 \% \mathrm{CI}]=0.029[0.010,0.048], p=$ 0.003 ; age: $\beta[95 \% \mathrm{CI}]=0.00009[-0.001,0.001], p=0.87$; male: $\beta[95 \% \mathrm{CI}]=-0.008[-0.025,0.008], p=0.33)$ and $\mathrm{FA}$ remained decreased (SCD cohort: $\beta[95 \% \mathrm{CI}]=-0.016$ $[-0.027,-0.005], p=0.005$; age: $\beta[95 \% \mathrm{CI}]=-0.0004$ $[-0.001,0.0002], p=0.23$; male: $\beta[95 \% \mathrm{CI}]=0.007$ $[-0.003,0.017], p=0.15)$.

\section{Cerebral Oxygen Metabolic Stress Was Associated With Microstructural Impairment in Adults With SCD but Not in Healthy Controls}

To examine whether cerebral oxygen metabolic or hemodynamic stress were associated with disruption in NAWM microstructure, we performed univariate and multivariable linear regression evaluating NAWM OEF and CBF as independent predictors of NAWM MD and FA. In the total cohort, on univariate analysis, NAWM OEF was significantly correlated with NAWM MD ( $\mathrm{r}=$ $0.306, p=0.002)$ and FA $(\mathrm{r}=-0.267, p=0.007)$. On multivariable analysis, after adjusting for age and scanner type, OEF remained an independent predictor of NAWM MD and FA (Table 3). On univariate analysis, NAWM CBF was nonsignificantly correlated with NAWM MD $(r=0.186, p=0.072)$ and not correlated with FA $(\mathrm{r}=-0.148, p=0.152)$. On multivariable analysis, $\mathrm{CBF}$ was not a predictor of $\mathrm{MD}$ and $\mathrm{FA}$ (Table 3).

To determine whether the association between cerebral oxygen metabolic stress and NAWM microstructure was cohort
Table 2 Baseline Oxygen Extraction Fraction (OEF), Cerebral Blood Flow (CBF), and Diffusion Tensor Imaging (DTI) Metrics in Control and Sickle Cell Disease (SCD) Cohorts

\begin{tabular}{llll}
\hline & $\begin{array}{l}\text { Controls } \\
(\mathbf{n}=\mathbf{4 9})\end{array}$ & $\mathbf{S C D}(\mathbf{n}=\mathbf{3 4})$ & $\boldsymbol{p}$ Value $^{\mathbf{a}}$ \\
\hline OEF & & & \\
\hline Whole brain & $0.27(0.25-0.28)$ & $0.37(0.32-0.42)$ & $\leq 0.001$ \\
\hline Gray matter & $0.29(0.26-0.30)$ & $0.37(0.34-0.43)$ & $\leq 0.001$ \\
\hline NAWM & $0.25(0.24-0.27)$ & $0.35(0.31-0.41)$ & $\leq 0.001$ \\
\hline CBF, mL/min/100 g & & & \\
\hline Whole brain & $62.0(54.0-66.6)$ & $81.2(74.2-99.3)$ & $\leq 0.001$ \\
\hline Gray matter & $68.6(56.4-75.3)$ & $90.4(82.6-114.4)$ & $\leq 0.001$ \\
\hline NAWM & $38.8(32.8-42.4)$ & $50.9(43.9-62.6)$ & $\leq 0.001$ \\
\hline $\begin{array}{l}\text { NAWM, MD, } \times \mathbf{1 0}^{-3} \\
\text { mm }^{2} \mathbf{s}^{-1}\end{array}$ & $0.72(0.70-0.77)$ & $0.76(0.74-0.78)$ & 0.005 \\
\hline NAWM, FA & $0.42(0.40-0.43)$ & $0.40(0.40-0.42)$ & 0.021 \\
\hline
\end{tabular}

Abbreviations: $F A$ = fractional anisotropy; $M D=$ mean diffusivity; NAWM = normal-appearing white matter.

Values are median (interquartile range).

${ }^{a}$ Raw $p$ values reported. Cohort differences in OEF, CBF, MD, and FA remained significant after adjusting for age and sex and correcting for multiple comparisons using the Benjamini-Hochberg procedure.

dependent, we performed the same regression within SCD and control cohorts separately. On univariate analysis, NAWM OEF was significantly correlated with $\mathrm{MD}(\mathrm{r}=0.35, p=0.014)$ and FA $(\mathrm{r}=-0.318, p=0.026)$ in the SCD cohort, but not in controls (MD: $\mathrm{r}=-0.116, p=0.407$; FA: $\mathrm{r}=0.112, p=0.425$ ). On multivariable analysis, after adjusting for age and scanner type, OEF remained associated with $\mathrm{MD}(\beta[95 \% \mathrm{CI}]=0.19$ $[0.02,0.36], p=0.035)$ and was nonsignificantly associated with FA $(\beta[95 \% \mathrm{CI}]=-0.11[-0.23,0.01], p=0.065)$ in the SCD cohort (Figure 1, A and $\mathrm{B}$, and Table 3 ). On univariate analysis, NAWM CBF was associated with $\mathrm{MD}(\mathrm{r}=0.34, p=0.026)$ and nonsignificantly associated with FA $(\mathrm{r}=-0.262, p=0.089)$ in the SCD cohort, but not in controls (MD: $\mathrm{r}=-0.197, p=0.161$; FA: $\mathrm{r}=0.201, p=0.153)$. On multivariable analysis, after adjusting for age and scanner type, $\mathrm{CBF}$ was not a predictor of $\mathrm{MD}$ and FA in either cohort (Figure 1, C and D, and Table 3).

\section{Spatial Locations of Elevated Cerebral Oxygen Metabolic Stress and Altered White Matter Integrity in Adults With SCD}

To locate the white matter regions with highest oxygen metabolic stress and greatest microstructural disruption in adults with SCD compared to controls, we performed voxelwise multivariable regression, using threshold-free cluster enhancement to identify significant voxels, after adjusting for age and scanner type. Participants with SCD demonstrated significantly higher OEF relative to controls throughout the majority of white matter, with loss of significance in the juxtacortical regions and voxels adjacent to the lateral ventricles 
Table 3 Mixed-Model Regression of Cerebral Hemodynamic (Cerebral Blood Flow [CBF]) and Oxygen Metabolic (Oxygen Extraction Fraction [OEF]) Stress as Independent Predictors of White Matter Microstructure

\begin{tabular}{|c|c|c|c|c|c|c|}
\hline \multirow{2}{*}{$\begin{array}{l}\text { Outcome variable } \\
\text { and predictor }\end{array}$} & \multicolumn{2}{|c|}{ Total cohort $(n=103 \text { MRIs })^{a}$} & \multicolumn{2}{|c|}{ Controls ( $n=53$ MRIs) } & \multicolumn{2}{|l|}{$S C D$ ( $n=50$ MRIs $)$} \\
\hline & $\beta(95 \% \mathrm{Cl})$ & $p$ Value & $\beta(95 \% \mathrm{Cl})$ & $p$ Value & $\beta(95 \% \mathrm{Cl})$ & $p$ Value \\
\hline \multicolumn{7}{|l|}{ NAWM MD } \\
\hline NAWM OEF & $0.13(0.03,0.23)$ & $0.013^{d}$ & $0.10(-2.54,2.73)$ & 0.72 & $0.19(0.02,0.36)$ & $0.035^{d}$ \\
\hline Scanner ${ }^{\mathbf{b}}$ & $0.04(0.03,0.05)$ & $<0.0001^{d}$ & $0.04(-0.01,0.18)$ & 0.16 & $0.04(0.02,0.05)$ & $<0.001^{\mathrm{d}}$ \\
\hline Age $^{c}$ & $0.00(0.00,0.00)$ & 0.844 & $0.00(-0.01,0.01)$ & 0.66 & $0.00(0.00,0.00)$ & 0.51 \\
\hline \multicolumn{7}{|l|}{ NAWM FA } \\
\hline NAWM OEF & $-0.08(-0.15,-0.02)$ & $0.02^{d}$ & $0.04(-1.67,1.75)$ & 0.82 & $-0.11(-0.23,0.01)$ & 0.065 \\
\hline Scanner ${ }^{\mathbf{b}}$ & $-0.01(-0.02,-0.01)$ & $0.003^{d}$ & $-0.01(-0.01,0.01)$ & 0.33 & $-0.01(-0.03,0.00)$ & $0.02^{\mathrm{d}}$ \\
\hline $\operatorname{Age}^{c}$ & $0.00(0.00,0.00)$ & 0.31 & $0.00(-0.10,0.08)$ & 0.46 & $0.00(0.00,0.00)$ & 0.71 \\
\hline \multicolumn{7}{|l|}{ NAWM MD } \\
\hline NAWM CBF & $0.00(0.00,0.00)$ & 0.56 & $0.00(-0.01,0.01)$ & 0.60 & $0.00(0.00,0.00)$ & 0.34 \\
\hline Scanner $^{\mathbf{b}}$ & $0.04(0.02,0.05)$ & $0.0002^{d}$ & $0.04(0.10,0.17)$ & 0.18 & $0.03(0.01,0.05)$ & $0.01^{d}$ \\
\hline Age $^{c}$ & $0.00(0.00,0.00)$ & 0.89 & $0.00(-0.01,0.01)$ & 0.58 & $0.00(0.00,0.00)$ & 0.76 \\
\hline \multicolumn{7}{|l|}{ NAWM FA } \\
\hline NAWM CBF & $0.00(0.00,0.00)$ & 0.37 & $0.00(0.00,0.01)$ & 0.43 & $0.00(0.00,0.00)$ & 0.19 \\
\hline Scanner ${ }^{\mathbf{b}}$ & $-0.01(-0.02,0.00)$ & $0.01^{d}$ & $-0.01(-0.10,0.08)$ & 0.36 & $-0.01(-0.02,0.01)$ & 0.18 \\
\hline Age $^{c}$ & $0.00(0.00,0.00)$ & 0.72 & $0.00(-0.01,0.01)$ & 0.42 & $0.00(0.00,0.00)$ & 0.86 \\
\hline $\begin{array}{l}\text { Abbreviations: } \mathrm{Cl}=\mathrm{c} \\
\text { a Each participant ha } \\
\text { b The most prevalen } \\
{ }^{\mathrm{C}} \text { Age, per 1-year incr } \\
\text { d Significant. }\end{array}$ & $\begin{array}{l}\text { interval; FA = fracti } \\
\text { scan except for } 4 \text { co } \\
\text { r type served as the }\end{array}$ & $\begin{array}{l}\text { nisotropy; 1 } \\
\text { articipants } \\
\text { nce. }\end{array}$ & $\begin{array}{l}\text { ean diffusivity; NAWI } \\
\text { participants with SC }\end{array}$ & $\begin{array}{l}\text { mal-app } \\
\text { had } 2 \text { se }\end{array}$ & $\begin{array}{l}\text { hite matter; } S C D=\text { si } \\
\text { is per person. }\end{array}$ & disease. \\
\hline
\end{tabular}

(Figure 2A). Compared to controls, participants with SCD had higher MD (Figure 2B) and lower FA (Figure 2C) in the deep white matter.

\section{Regions of Oxygen Metabolic Stress Include and Surround Deep White Matter Regions of Impaired Microstructure, Which in Turn Extend Beyond Regions of Peak Infarct Density}

The infarct density map from the SCD cohort demonstrated infarcts in a small, deep, white matter region of the frontal and parietal lobes with maximal infarct density of $20 \%$ (Figure $3 \mathrm{~A}$ ). First, we investigated the spatial relationship of disrupted white matter microstructure and cerebral oxygen metabolic stress by overlaying the map of voxels with significantly elevated $\mathrm{MD}$ onto the map of voxels with significantly elevated OEF (Figure 3B). Regions of OEF elevation colocalized with and extended beyond regions of impaired white matter microstructure. Next, we examined the spatial relationship between infarct location and white matter microstructure by overlaying the infarct density map onto the map of voxels with elevated MD. Regions of significant MD elevation in the deep white matter surrounded and extended beyond cerebral infarcts. Together, these findings suggest that oxygen metabolic stress may underlie disruption in white matter microstructure, which appears at the leading edge of developing cerebral infarcts.

\section{Discussion}

In adults with SCD, we found that cerebral oxygen metabolic stress, defined as elevated OEF, was associated with microstructural impairment in radiographically normal white matter. Hemodynamic stress, defined as elevated CBF, was associated with NAWM microstructural disruption on univariate analysis only. Importantly, associations between $\mathrm{OEF}, \mathrm{CBF}$, and impaired white matter microstructure were absent in healthy controls where blood flow and oxygen metabolism are normal. In the voxel-wise analysis comparing the SCD cohort to the control cohort, a region of elevated $\mathrm{MD}$ was located in the deep supraventricular white matter, and was surrounded by a larger region of elevated white matter OEF that extended towards the cortex. The region of peak infarct density within the SCD cohort was centered within the region of elevated $\mathrm{MD}$, suggesting that white matter microstructural impairment is located at the leading edge of cerebral infarct development in SCD. We are performing 
Figure 1 White Matter Oxygen Extraction Fraction (OEF) is Associated With White Matter Microstructural Injury in Participants With Sickle Cell Disease (SCD)
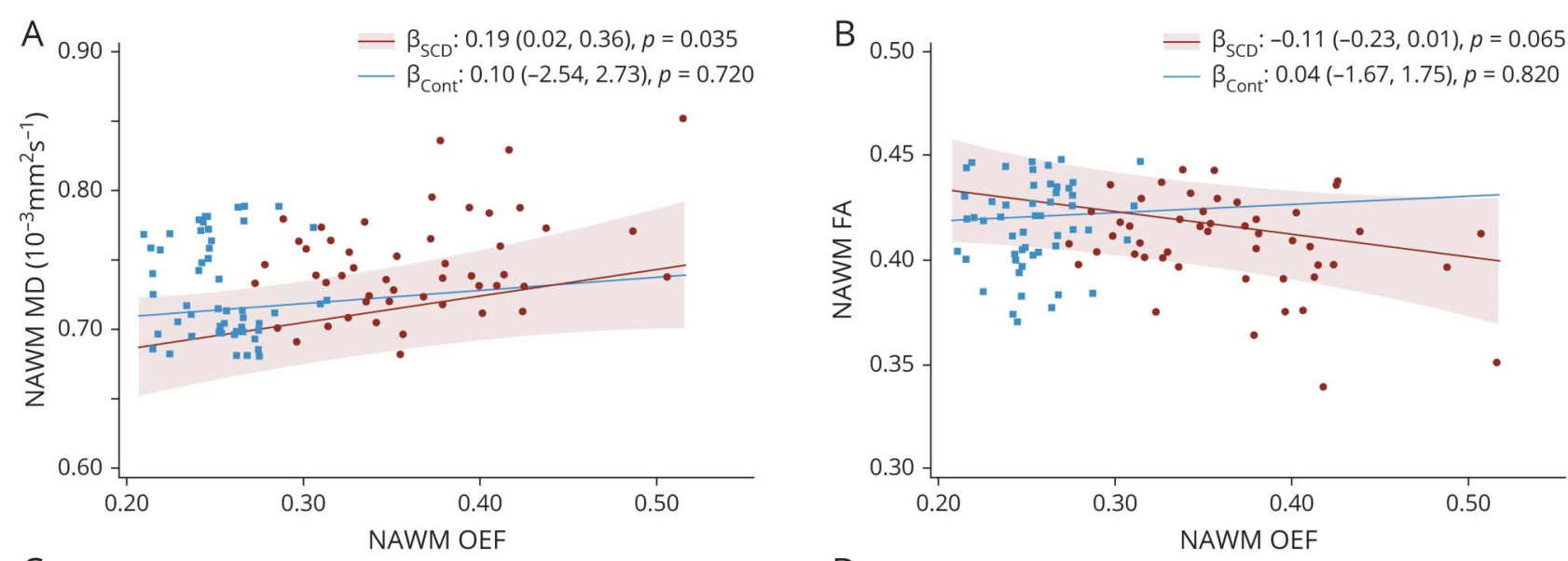

C

D
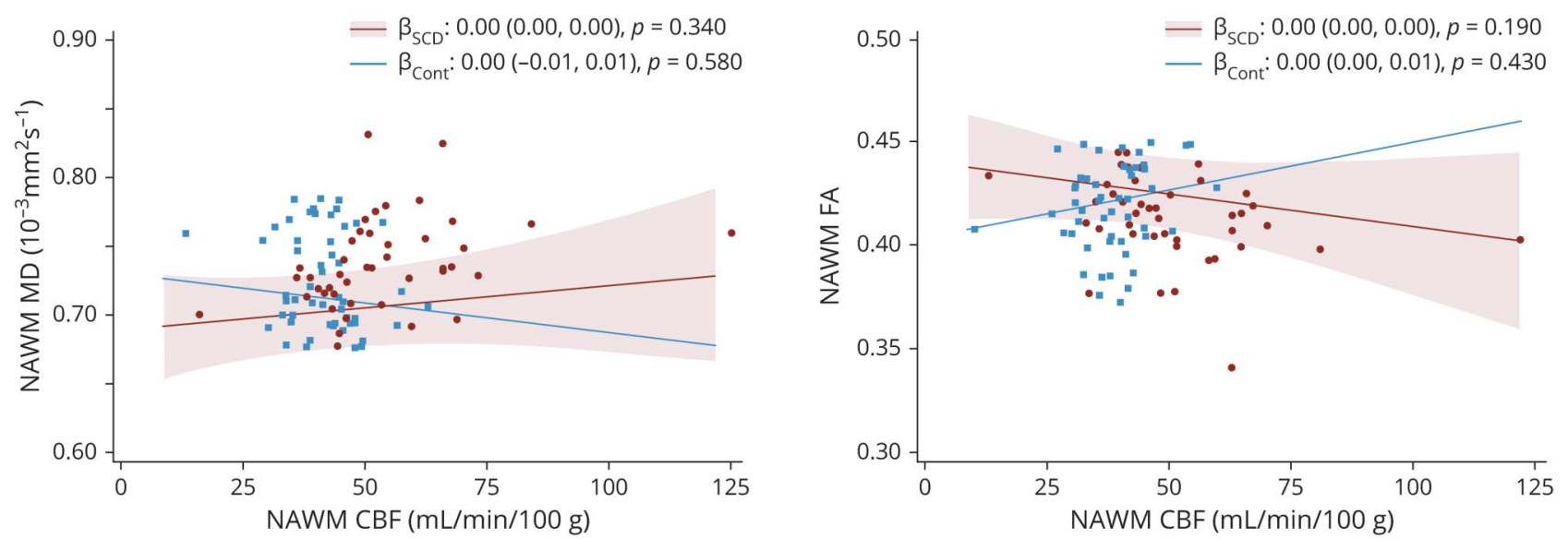

Relationships between normal-appearing white matter (NAWM) OEF/cerebral blood flow (CBF) vs NAWM mean diffusivity (MD)/fractional anisotropy (FA) are shown after performing linear mixed-model regressions adjusted for age, participants with multiple MRI scans, and scanner type. All effect plots were calculated at the median cohort age of 29.0 years and the most prevalent scanner type as the reference scanner. In participants with SCD, NAWM OEF was associated with MD (A) and nonsignificantly associated with FA (B), while no association was found between OEF and diffusion tensor imaging metrics in controls. NAWM CBF was not associated with MD (C) or FA (D) in either cohort. 95\% Confidence intervals for the control cohort were excluded for simplicity.

longitudinal studies to determine whether impairment in white matter microstructure temporally progresses from NAWM to cerebral infarct.

Microstructural disruption and radiographic infarcts may be viewed as part of a continuum, determined by the magnitude and duration of ischemia. Mild and intermittent reduction in cerebral oxygen supply may result in interstitial fluid shifts and demyelination, causing reversible microstructural injury, while prolonged, severe decrease may result in irreversible cell death. ${ }^{36}$ Whereas the spatial-temporal progression from white matter microstructural disruption to cerebral infarct has been demonstrated in non-SCD sporadic cerebral small vessel disease, ${ }^{16,37,38}$ such evolution has not been studied in SCD. In the absence of longitudinal data, we examined the spatial relationship between microstructural integrity and infarct location in the early stages of SCD using a young adult cohort with low infarct burden. Consistent with previously published research, ${ }^{10-12}$ we found evidence for microstructural injury, defined by elevation in MD and reduction in FA, in the deep white matter tracts. Expanding on prior investigations, we found that a penumbra of microstructural disruption surrounds and extends beyond the borders of peak cerebral infarct density. Similarly, studies in non-SCD sporadic small vessel disease have shown that white matter hyperintensities are surrounded by a penumbra of reduced cerebral perfusion and compromised white matter microstructural integrity that normalized with increasing distance from the white matter hyperintensity core. $^{39,40}$ Identifying tissue with microstructural injury but without infarction presents an opportunity for intervention to prevent future infarct and progression in cognitive impairment.

The association between elevated OEF and DTI abnormalities within NAWM suggests that oxygen metabolic stress may play a role in white matter microstructural impairment prior to frank infarction. Consistent with our prior research in the pediatric population and expanding upon the findings by Jordan et al., ${ }^{8}$ which showed global elevation of OEF in an 
Figure 2 Adults With Sickle Cell Disease (SCD) Demonstrate Widespread Oxygen Metabolic Stress and Microstructural Injury in Deep White Matter Regions
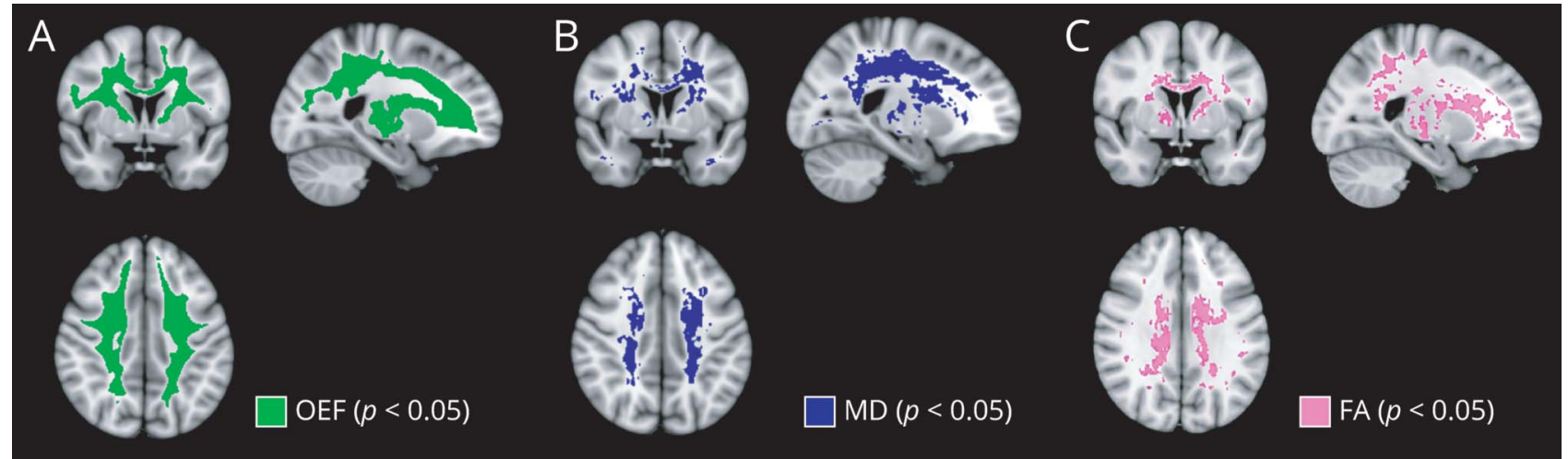

Voxel-wise nonparametric statistical comparisons between the SCD and control cohorts were performed with corrections for multiple voxel-wise comparisons using threshold-free cluster enhancement and adjusted for age and scanner type. Voxels with statistically significant differences in oxygen extraction fraction (OEF), mean diffusivity (MD), and fractional anisotropy (FA) between SCD and control cohorts at $p<0.05$ are displayed. (A) OEF was elevated throughout the white matter of adults with $S C D$, with significance lost in the juxtacortical regions and adjacent to the lateral ventricles. In addition, the SCD cohort demonstrated increased MD (B) and decreased FA (C) relative to controls, predominately in the deep white matter.

adult SCD population, we found elevated tissue-type specific cerebral OEF and $\mathrm{CBF}$ in adults with SCD relative to controls. ${ }^{6,8,41}$ We are currently evaluating global and regional $\mathrm{OEF}$ as predictors of infarct progression in SCD. We postulate that OEF may risk stratify microstructural impairment prior to irreversible structural damage. In support of our findings showing a relationship between oxygen metabolic stress and microstructural integrity, Fields et al. ${ }^{42}$ identified an association between oxygen metabolic stress and diminished functional connectivity in white matter unaffected by infarcts in children with SCD. In non-SCD sporadic small vessel disease, impairment in cerebrovascular reactivity, a metric of cerebral autoregulation, has been associated with disruption in microstructural integrity. ${ }^{43}$ Together, these studies contribute to the notion that inadequate oxygen delivery and elevation in oxygen metabolic stress may underlie the pathophysiology of microstructural disruption in SCD.

In contrast, $\mathrm{CBF}$ elevation was not associated with microstructural impairment. Potential explanations include that CBF may be a less sensitive marker of hypoxia than OEF. In contrast to acute ischemic stroke, where cerebral perfusion

Figure 3 Spatial Relationship Between Oxygen Metabolic Stress, White Matter Microstructural Injury, and Cerebral Infarcts

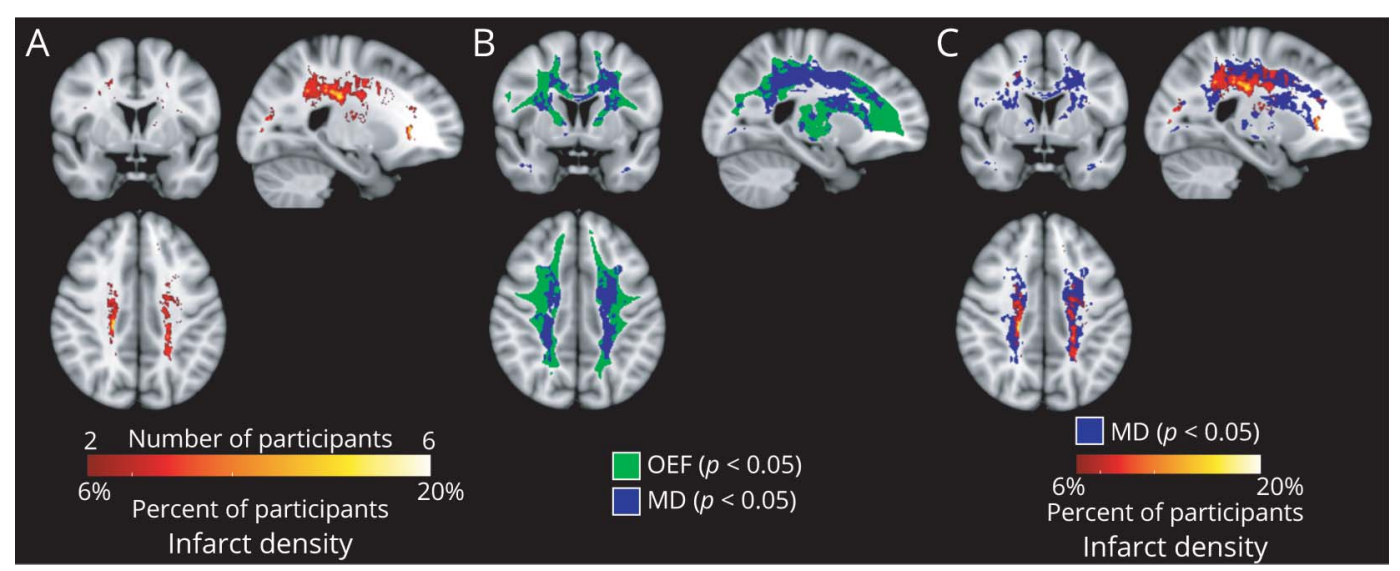

(A) Infarct density map was calculated from fluid-attenuated inversion recovery lesion maps in the sickle cell disease (SCD) cohort, defined as number of participants with infarcts in the voxel, divided by total number of participants, thresholded to include at least 2 participants with infarcts in the voxel. (B) To determine the spatial relationship between impairment in white matter microstructure and oxygen metabolic stress, the map of voxels with elevated mean diffusivity (MD) was overlaid onto the map of voxels with elevated oxygen extraction fraction (OEF). Regions of significant OEF elevation colocalized with and extended beyond regions of significant microstructural impairment. (C) To determine the spatial relationship between infarct location and white matter microstructural injury, the infarct density map was overlaid onto the map of voxels with elevated MD. The region of elevated MD surrounded and extended beyond the borders of the cerebral infarcts, suggesting that microstructural injury in normal-appearing white matter may be a precursor to infarct development in SCD. 
pressure and $\mathrm{CBF}$ precipitously drop, $\mathrm{CBF}$ in $\mathrm{SCD}$ is chronically elevated and plateaus with maximal arterial dilation. OEF may subsequently increase to provide additional oxygen reserve and responds more readily to fluctuations in oxygen availability. ${ }^{41,44}$ Second, CBF is highly variable, even in healthy individuals. ${ }^{45}$ We have recently measured the repeatability of pCASL CBF in healthy adults, finding substantially worse (higher coefficient of variation) repeatability than that of ASE OEF (manuscript in preparation). Lastly, CBF measurements in the white matter are limited by the low signal-to-noise ratio (SNR) using pCASL. ${ }^{46}$ Thus, we postulate that both biological and methodologic reasons explain a lower association of $\mathrm{CBF}$ and microstructural integrity in SCD.

Our study has several strengths. For the patient-based analysis, we excluded regions of prior infarct, permitting quantification of cerebral oxygen metabolic stress as an independent predictor of microstructural impairment within radiographically normal white matter. We employed tissue-based MRI measures of $\mathrm{CBF}$ and $\mathrm{OEF}$, which allowed us to perform a voxel-wise analysis across white matter to examine the spatial relationships between regional cerebral oxygen metabolic stress, white matter microstructure, and infarct location at the voxel level. An additional strength of our cohort was the ability to include participants with small infarct volumes to evaluate the microstructural impairment in close proximity to infarct location. Whereas the prevalence and volume of infarcts in the control cohort were significantly smaller than those of the SCD cohort, $39 \%$ of the control cohort had evidence of silent cerebral infarcts on MRI. The results underscore the importance of including a control group when examining infarct prevalence in SCD given nonspecific white matter lesions are common in adults outside of SCD.

Our study has several limitations. We performed a crosssectional analysis of prospectively collected MRI data, which limits our ability to assess causality. Whereas our data show that microstructural ischemic injury is adjacent to and more extensive than cerebral infarcts, we are following participants longitudinally to measure the temporal relationship between oxygen metabolic stress, microstructural disruption, and infarct development. We have not measured the association of our findings with cognitive consequences of SCD, which represent a major cause of disability and loss of independence for individuals with SCD. We have recently started performing full cognitive assessments to prevent this limitation in future studies. The cohorts are unbalanced with respect to age and sex between the 2 cohorts, in part due to difficulty in our ability to recruit younger, male healthy controls from the SCD clinic. As our SCD cohort was younger than the controls, we anticipated perhaps smaller differences in the DTI metrics, yet we found impairment in NAWM microstructure in the younger SCD cohort, even prior to adjusting for age. Furthermore, we continued to find differences in all baseline imaging measures between the 2 cohorts, after adjusting for age and sex imbalance. Due to logistics of scheduling, participants were scanned on 1 of 3 research scanners at our institution, whereas a single scanner would have been optimal. Indeed, we identified a significant effect of scanner type on the DTI values, as has been found in other studies. ${ }^{31,32}$ Our control cohort included sibling controls when possible to balance the 2 cohorts across socioeconomic status, thus controls with $\mathrm{HbAS}$ were permitted. Whereas the impact of sickle cell trait on multiple organ systems is debated, ${ }^{47}$ in a separate analysis, we found no differences in the CBF, OEF, and microstructural integrity in controls with $\mathrm{HbAS}$ compared to HbAA. If there was an effect of sickle cell trait towards our findings in the SCD cohort, this would lessen the differences between the control and SCD cohorts.

Lastly, there are specific limitations with respect to the OEF and CBF measurements. The OEF values measured using the ASE technique are lower than those measured by ${ }^{15} \mathrm{O}-\mathrm{PET}$, in part due to water diffusion effects, which affect extravascular signal. ${ }^{48,49}$ In a preclinical study, we found a highly linear correlation of cerebral oxygen saturation measured via ASE MRI and blood gas oximetry across a wide range of global cerebral oxygenation in rats. ${ }^{26}$ Whereas the absolute OEF differs between the MRI and PET methods, the relative differences between control and SCD cohorts and the significant association between OEF and white matter microstructure should remain valid. We are comparing MRI-measured and ${ }^{15} \mathrm{O}-\mathrm{PET}$ measured OEF in healthy participants within a separate study. Further sources of error in OEF quantification include background susceptibility effects and Gibb artifact, which are accounted for by a priori exclusion of voxels with poor model fit, as described in the Methods. As discussed above, white matter CBF using pCASL may be limited by the relatively low SNR and poor repeatability, as well as varying arterial transit times between gray and white matter and between healthy adults and adults with SCD. Previous studies, however, have suggested that using a protocol and postlabel delay similar to one employed in this study will likely yield adequate labeling and SNR to permit accurate measures of white matter CBF. ${ }^{46}$

Elevated cerebral OEF was independently associated with microstructural impairment in NAWM in adults with SCD, but not in healthy controls. Within high OEF regions, we found disruption in white matter microstructure that spatially extended beyond cerebral infarcts. Longitudinal imaging studies with cognitive assessment will help to determine whether cerebral oxygen metabolic stress temporally predicts microstructural and structural ischemic brain injury, as well as cognitive disability, in SCD. New SCD therapies aimed to strengthen hemoglobin-oxygen binding could lower cerebral oxygen metabolic stress and maintain oxygen reserve ${ }^{50}$; however, studies are required to measure neurologic and safety outcomes after treatment ${ }^{51}$. Cerebral metabolic stress may therefore serve as a potential therapeutic target, allowing physicians to tailor preventative strategies before microstructural injury and stroke occur.

\section{Study Funding}

NIH NHLBI R01HL129241 (A.L.F.), NIH NHLBI K23 HL136904 (M.E.F.), NIH NINDS K23 NS099472 (K.P.G.). 


\section{Disclosure}

The authors report no disclosures relevant to the manuscript. Go to Neurology.org/N for full disclosures.

\section{Publication History}

Received by Neurology January 14, 2021. Accepted in final form May 26, 2021.

\section{Appendix Authors}

\begin{tabular}{|c|c|c|}
\hline Name & Location & Contribution \\
\hline $\begin{array}{l}\text { Yan Wang, } \\
\text { MD }\end{array}$ & $\begin{array}{l}\text { Washington University } \\
\text { School of Medicine, St. } \\
\text { Louis, MO }\end{array}$ & $\begin{array}{l}\text { Designed the study, performed } \\
\text { the analysis, interpreted the } \\
\text { data, and drafted the manuscript }\end{array}$ \\
\hline $\begin{array}{l}\text { Slim Fellah, } \\
\text { PhD }\end{array}$ & $\begin{array}{l}\text { Washington University } \\
\text { School of Medicine, St. } \\
\text { Louis, MO }\end{array}$ & $\begin{array}{l}\text { Acquired the data, performed } \\
\text { the analysis, interpreted the } \\
\text { data, and drafted the manuscript }\end{array}$ \\
\hline $\begin{array}{l}\text { Melanie E. } \\
\text { Fields, MD, } \\
\text { MSCI }\end{array}$ & $\begin{array}{l}\text { Washington University } \\
\text { School of Medicine, St. } \\
\text { Louis, MO }\end{array}$ & $\begin{array}{l}\text { Acquired the data and edited the } \\
\text { manuscript }\end{array}$ \\
\hline $\begin{array}{l}\text { Kristin P. } \\
\text { Guilliams, } \\
\text { MD, MSCI }\end{array}$ & $\begin{array}{l}\text { Washington University } \\
\text { School of Medicine, St. } \\
\text { Louis, MO }\end{array}$ & $\begin{array}{l}\text { Acquired the data and edited the } \\
\text { manuscript }\end{array}$ \\
\hline $\begin{array}{l}\text { Michael M. } \\
\text { Binkley, PhD }\end{array}$ & $\begin{array}{l}\text { Washington University } \\
\text { School of Medicine, St. } \\
\text { Louis, MO }\end{array}$ & $\begin{array}{l}\text { Acquired the data, performed } \\
\text { the statistical analysis, and } \\
\text { edited the manuscript }\end{array}$ \\
\hline $\begin{array}{l}\text { Cihat } \\
\text { Eldeniz, PhD }\end{array}$ & $\begin{array}{l}\text { Washington University } \\
\text { School of Medicine, St. } \\
\text { Louis, MO }\end{array}$ & $\begin{array}{l}\text { Acquired the data and } \\
\text { performed the analysis }\end{array}$ \\
\hline $\begin{array}{l}\text { Joshua S. } \\
\text { Shimony, } \\
\text { MD, PhD }\end{array}$ & $\begin{array}{l}\text { Washington University } \\
\text { School of Medicine, St. } \\
\text { Louis, MO }\end{array}$ & $\begin{array}{l}\text { Acquired the data and } \\
\text { performed the analysis }\end{array}$ \\
\hline $\begin{array}{l}\text { Martin Reis, } \\
\text { MD }\end{array}$ & $\begin{array}{l}\text { Washington University } \\
\text { School of Medicine, St. } \\
\text { Louis, MO }\end{array}$ & $\begin{array}{l}\text { Acquired the data and } \\
\text { performed the analysis }\end{array}$ \\
\hline $\begin{array}{l}\text { Katie D. Vo, } \\
\text { MD }\end{array}$ & $\begin{array}{l}\text { Washington University } \\
\text { School of Medicine, St. } \\
\text { Louis, MO }\end{array}$ & $\begin{array}{l}\text { Acquired the data and } \\
\text { performed the analysis }\end{array}$ \\
\hline $\begin{array}{l}\text { Yasheng } \\
\text { Chen, DSc }\end{array}$ & $\begin{array}{l}\text { Washington University } \\
\text { School of Medicine, St. } \\
\text { Louis, MO }\end{array}$ & $\begin{array}{l}\text { Acquired the data and } \\
\text { performed the analysis }\end{array}$ \\
\hline $\begin{array}{l}\text { Jin-Moo Lee, } \\
\text { MD, PhD }\end{array}$ & $\begin{array}{l}\text { Washington University } \\
\text { School of Medicine, St. } \\
\text { Louis, MO }\end{array}$ & $\begin{array}{l}\text { Conceived and designed the } \\
\text { study }\end{array}$ \\
\hline $\begin{array}{l}\text { Hongyu An, } \\
\text { DSc }\end{array}$ & $\begin{array}{l}\text { Washington University } \\
\text { School of Medicine, St. } \\
\text { Louis, MO }\end{array}$ & $\begin{array}{l}\text { Conceived and designed the } \\
\text { study }\end{array}$ \\
\hline $\begin{array}{l}\text { Andria L. } \\
\text { Ford, MD, } \\
\text { MSCI }\end{array}$ & $\begin{array}{l}\text { Washington University } \\
\text { School of Medicine, St. } \\
\text { Louis, MO }\end{array}$ & $\begin{array}{l}\text { Conceived and designed the } \\
\text { study, performed the analysis, } \\
\text { interpreted the data, and drafted } \\
\text { the manuscript }\end{array}$ \\
\hline
\end{tabular}

\section{References}

1. Piel FB, Hay SI, Gupta S, Weatherall DJ, Williams TN. Global burden of sickle cell anaemia in children under five, 2010-2050: modelling based on demographics, excess mortality, and interventions. PLoS Med. 2013;10(7):e1001484.

2. Bernaudin F, Verlhac S, Arnaud C, et al. Impact of early transcranial Doppler screening and intensive therapy on cerebral vasculopathy outcome in a newborn sickle cell anemia cohort. Blood. 2011;117(4):1130-1140.

3. Kassim AA, Pruthi S, Day M, et al. Silent cerebral infarcts and cerebral aneurysms are prevalent in adults with sickle cell anemia. Blood. 2016;127(16):2038-2040.
4. Vichinsky EP, Neumayr LD, Gold JI, et al. Neuropsychological dysfunction and neuroimaging abnormalities in neurologically intact adults with sickle cell anemia. JAMA. 2010;303(18):1823-1831.

5. Schatz J, Brown RT, Pascual JM, Hsu L, DeBaun MR. Poor school and cognitive functioning with silent cerebral infarcts and sickle cell disease. Neurology. 2001;56(8): 1109-1111.

6. Ford AL, Ragan DK, Fellah S, et al. Silent infarcts in sickle cell disease occur in the border zone region and are associated with low cerebral blood flow. Blood. 2018; 132(16):1714-1723.

7. Fields ME, Guilliams KP, Ragan DK, et al. Regional oxygen extraction predicts border zone vulnerability to stroke in sickle cell disease. Neurology. 2018;90(13):e1134-e1144.

8. Jordan LC, Gindville MC, Scott AO, et al. Non-invasive imaging of oxygen extraction fraction in adults with sickle cell anaemia. Brain. 2016;139(3):738-750.

9. Chai $\mathrm{Y}$, Bush AM, Coloigner J, et al. White matter has impaired resting oxygen delivery in sickle cell patients. Am J Hematol. 2019;94(4):467-474.

10. Balci A, Karazincir S, Beyoglu Y, et al. Quantitative brain diffusion-tensor MRI findings in patients with sickle cell disease. Am J Roentgenol. 2012;198(5):1167-1174.

11. Jacob M, Stotesbury H, Kawadler JM, et al. White matter integrity in Tanzanian children with sickle cell anemia. Stroke. 2020;51(4):1166-1173.

12. Sun B, Brown RC, Hayes L, et al. White matter damage in asymptomatic patients with sickle cell anemia: screening with diffusion tensor imaging. Am J Neuroradiol. 2012; 33(11):2043-2049.

13. Scantlebury N, Mabbott D, Janzen L, et al. White matter integrity and core cognitive function in children diagnosed with sickle cell disease. J Pediatr Hematol Oncol. 2011; 33(3):163-171.

14. Stotesbury H, Kirkham FJ, Kölbel M, et al. White matter integrity and processing speed in sickle cell anemia. Neurology. 2018;90:e2042-e2050.

15. Kantarci K, Senjem ML, Avula R, et al. Diffusion tensor imaging and cognitive function in older adults with no dementia. Neurology. 2011;77(1):26-34.

16. Promjunyakul NO, Dodge HH, Lahna D, et al. Baseline NAWM structural integrity and CBF predict periventricular WMH expansion over time. Neurology. 2018;90(24): e2107-e2118.

17. King AA, Rodeghier MJ, Panepinto JA, et al. Silent cerebral infarction, income, and grade retention among students with sickle cell anemia. Am J Hematol. 2014;89(10): E188-E192.

18. Casella JF, King AA, Barton B, et al. Design of the silent cerebral infarct transfusion (SIT) trial. Pediatr Hematol Oncol. 2010;27(2):69-89.

19. Caboot JB, Jawad AF, McDonough JM, et al. Non-invasive measurements of carboxyhemoglobin and methemoglobin in children with sickle cell disease. Pediatr Pulmonol. 2012;47(8):808-815.

20. Frackowiak RSJ, Frith CD, Price CJ, et al. Human Brain Function, 2nd ed. Elsevier; 2003.

21. Asllani I, Borogovac A, Brown TR. Regression algorithm correcting for partial volume effects in arterial spin labeling MRI. Magn Reson Med. 2008;60(6):1362-1371.

22. Wang T, Li Y, Guo X, et al. Reduced perfusion in normal-appearing white matter in mild to moderate hypertension as revealed by $3 \mathrm{D}$ pseudocontinuous arterial spin labeling. J Magn Reson Imaging. 2016;43(3):635-643.

23. Jain V, Duda J, Avants B, et al. Longitudinal reproducibility and accuracy of pseudocontinuous arterial spin-labeled perfusion MR imaging in typically developing children. Radiology. 2012;263(2):527-536.

24. Eldeniz C, Finsterbusch J, Lin W, An H. TOWERS: T-one with enhanced robustness and speed. Magn Reson Med. 2016;76(1):118-126.

25. Hales PW, Kirkham FJ, Clark CA. A general model to calculate the spin-lattice (T1) relaxation time of blood, accounting for haematocrit, oxygen saturation and magnetic field strength. J Cereb Blood Flow Metab. 2016;36(2):370-374.

26. An H, Lin W. Impact of intravascular signal on quantitative measures of cerebral oxygen extraction and blood volume under normo- and hypercapnic conditions using an asymmetric spin echo approach. Magn Reson Med. 2003;50(4):708-716.

27. An H, Liu Q, Chen Y, Lin W. Evaluation of MR-derived cerebral oxygen metabolic index in experimental hyperoxic hypercapnia, hypoxia, and ischemia. Stroke. 2009; 40(6):2165-2172.

28. Jenkinson M, Beckmann CF, Behrens TEJ, Woolrich MW, Smith SM. FSL. Neuroimage. 2012;62(2):782-790.

29. Smith SM, Jenkinson M, Johansen-Berg H, et al. Tract-based spatial statistics: voxelwise analysis of multi-subject diffusion data. Neuroimage. 2006;31(4):1487-1505.

30. Basser PJ, Mattiello J, Lebihan D. Estimation of the effective self-diffusion tensor from the NMR spin echo. J Magn Reson Ser B. 1994;103(3):247-254.

31. Fortin JP, Parker D, Tunç B, et al. Harmonization of multi-site diffusion tensor imaging data. Neuroimage. 2017;161:149-170.

32. Mohammadi S, Nagy Z, Möller HE, et al. The effect of local perturbation fields on human DTI: characterisation, measurement and correction. Neuroimage. 2012;60(1): 562-570.

33. Nichols TE, Holmes AP. Nonparametric permutation tests for functional neuroimaging: a primer with examples. Hum Brain Mapp. 2002;15(1):1-25.

34. Winkler AM, Ridgway GR, Webster MA, Smith SM, Nichols TE. Permutation inference for the general linear model. Neuroimage. 2014;92(100):381-397.

35. Smith SM, Nichols TE. Threshold-free cluster enhancement: addressing problems of smoothing, threshold dependence and localisation in cluster inference. Neuroimage. 2009;44(1):83-98

36. Wardlaw JM, Valdés Hernández MC, Muñoz-Maniega $\mathrm{S}$. What are white matter hyperintensities made of? J Am Heart Assoc. 2015;4(6):001140.

37. De Groot M, Verhaaren BFJ, De Boer R, et al. Changes in normal-appearing white matter precede development of white matter lesions. Stroke. 2013;44(4):1037-1042. 
38. van Leijsen EMC, Bergkamp MI, van Uden IWM, et al. Progression of white matter hyperintensities preceded by heterogeneous decline of microstructural integrity. Stroke. 2018;49(6):1386-1393.

39. Promjunyakul N-O, Lahna DL, Kaye JA, et al. Comparison of cerebral blood flow and structural penumbras in relation to white matter hyperintensities: a multi-modal magnetic resonance imaging study. J Cereb Blood Flow Metab. 2016;36:1528-1536.

40. Maniega SM, Valdés Hernández MC, Clayden JD, et al. White matter hyperintensities and normal-appearing white matter integrity in the aging brain. Neurobiol Aging. 2015; 36(2):909-918

41. Fields ME, Guilliams KP, Ragan D, et al. Hydroxyurea reduces cerebral metabolic stress in patients with sickle cell anemia. Blood. 2019;133(22):2436-2444.

42. Fields ME, Mirro AE, Guilliams KP, et al. Functional connectivity decreases with metabolic stress in sickle cell disease. Ann Neurol. 2020:25891.

43. Sam K, Peltenburg B, Conklin J, et al. Cerebrovascular reactivity and white matter integrity. Neurology. 2016;87(22):2333-2339.

44. Guilliams KP, Fields ME, Ragan DK, et al. Red cell exchange transfusions lower cerebral blood flow and oxygen extraction fraction in pediatric sickle cell anemia. Blood. 2018;131(9):1012-1021.
45. Chen Y, Wang DJJ, Detre JA. Test-retest reliability of arterial spin labeling with common labeling strategies. J Magn Reson Imaging. 2011;33(4):940-949.

46. Wu WC, Lin SC, Wang DJ, Chen KL, Li YD. Measurement of cerebral white matter perfusion using pseudocontinuous arterial spin labeling 3T magnetic resonance imaging: an experimental and theoretical investigation of feasibility. PLoS One. 2013; $8(12)$.

47. Tsaras G, Owusu-Ansah A, Boateng FO, Amoateng-Adjepong Y. Complications associated with sickle cell trait: a brief narrative review. Am JMed. 2009;122(6):507-512.

48. Leenders K, Perani D, Lammertsma A, et al. Cerebral blood flow, blood volume and oxygen utilization: normal values and effect of age. Brain. 1990;113(1):27-47.

49. Stone AJ, Holland NC, Berman AJL, Blockley NP. Simulations of the effect of diffusion on asymmetric spin echo based quantitative BOLD: an investigation of the origin of deoxygenated blood volume overestimation. Neuroimage. 2019;201:116035.

50. Vichinsky E, Hoppe CC, Ataga KI, et al. A phase 3 randomized trial of voxelotor in sickle cell disease. N Engl J Med. 2019;381(6):509-519.

51. Stotesbury H, Kawadler JM, Hales PW, et al. Vascular instability and neurological morbidity in sickle cell disease: an integrative framework. Front Neurol. 2019;(10): 871. 


\section{Neurology}

\section{Cerebral Oxygen Metabolic Stress, Microstructural Injury, and Infarction in Adults With Sickle Cell Disease}

Yan Wang, Slim Fellah, Melanie E. Fields, et al.

Neurology 2021;97;e902-e912 Published Online before print June 25, 2021

DOI 10.1212/WNL.0000000000012404

This information is current as of June 25, 2021

\section{Updated Information \& Services}

References

Citations

Subspecialty Collections

Permissions \& Licensing

Reprints including high resolution figures, can be found at: http://n.neurology.org/content/97/9/e902.full

This article cites 47 articles, 15 of which you can access for free at: http://n.neurology.org/content/97/9/e902.full\#ref-list-1

This article has been cited by 1 HighWire-hosted articles: http://n.neurology.org/content/97/9/e902.full\#\#otherarticles

This article, along with others on similar topics, appears in the following collection(s):

MRI

http://n.neurology.org/cgi/collection/mri

Stroke in young adults

http://n.neurology.org/cgi/collection/stroke_in_young_adults

Information about reproducing this article in parts (figures,tables) or in its entirety can be found online at:

http://www.neurology.org/about/about_the_journal\#permissions

Information about ordering reprints can be found online:

http://n.neurology.org/subscribers/advertise

Neurology ${ }^{\circledR}$ is the official journal of the American Academy of Neurology. Published continuously since 1951, it is now a weekly with 48 issues per year. Copyright Copyright (C) 2021 The Author(s). Published by Wolters Kluwer Health, Inc. on behalf of the American Academy of Neurology.. All rights reserved. Print ISSN: 0028-3878. Online ISSN: 1526-632X.

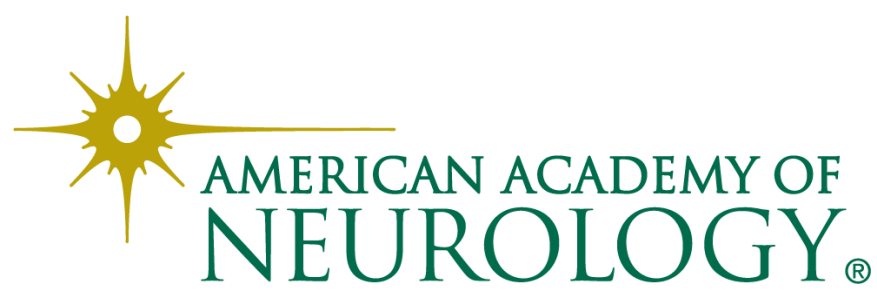

